\title{
Analysis of open innovation practices in the Iranian power industry
}

\author{
Jafar Bagherinejad $^{\mathrm{a}}$ and Mehdi Darjazini ${ }^{\mathrm{b}}{ }^{*}$
}

${ }^{a}$ Faculty member, Department of Engineering, Alzahra University, Tehran, Iran

${ }^{b}$ Master student of Science of MBA Technology, University of Science of Economy, Iran

\section{CHRON I C L E}

Article history:

Received June 22, 2013

Received in revised format

28 August 2013

Accepted 25 September 2013

Available online

September 272013

Keywords:

Open Innovation

Open innovation Practice

Electricity Generation

\section{A B S T R A C T}

Open innovation has become one of the hottest topics in innovation management. In this study, after reviewing the relevant literature, a conceptual framework is designed. This framework has been tested and proved in a field study in the Iranian power industry. Gathered data has been processed by Exploratory Factor Analysis in SPSS software. The results of this research shows that Iranian electricity generating companies use four approaches including Selling out and Leakage of technology, Acquisition of Technology, Acquisition of Firms and Projects, and Spin offs and Divestment, in their open innovation processes respectively.

\section{Introduction}

During the past few years, many business models look for shorter innovation cycles because of industrial research and development's escalating costs as well as the dearth of resources. In fact, there is a growing increase on globalization of research, technologies and innovation and this happens through new information and communication technologies as well as organizational forms and the potentials of business models. Only companies wishing to commercialize their own ideas as well as other firms' innovation are able to start an "era of open innovation".

Many firms have recently started to implement open innovation as a necessary organizational adaptation to changes in the environment (Chesbrough, 2003). In a world of mobile workers, abundant venture capital, widely distributed knowledge and reduced product life cycles, most enterprises are not able to have innovation on their own. It is anticipated that basic entrepreneurial values such as growth and revenues will be among the key motives of enterprises to practice open innovation (Chesbrough \& Crowther, 2006).

*Corresponding author.

E-mail address: m.darjazini@gmail.com (M. Darjazini) 
These days, most firms need flexible innovation strategies to cope with changing environment. Creating a new, flexible innovation strategy means combining various approaches that take market demands and the company's vision into account (Gassmann \& Enkel, 2004). Researchers have suggested various kinds of strategies and ways to categorized them (Gassmann \& Enkel, 2004; Herzog, 2011; Van de Vrande, De Jong, Vanhaverbeke, \& De Rochemont, 2009). Most of these researches have been conducted in developed countries. Therefore, it is essential to study on similar practices in developing countries to help their companies understand open innovation and its practices. Moreover, categorizing these practices to understand approaches among bunch of open innovation practices will be great helpful tool for managers.

There are a lot of practices with almost the same definitions and various names and different types of categorizes, which lead researchers to encounter with inconvenience to use in their researches. In addition, all of these are not implemented in Iran and do not have the same prevalence. As a result, reconsideration of categorizing and definition of these methods are necessary. In this article, we review these methods and their definitions. In addition, by using exploratory factor analysis, we try to categorize these practices in order to provide clear framework to open innovation.

\section{Literature review}

Open innovation has been proposed as a new paradigm for the management of innovation ( Chesbrough, 2006; Gassmann, 2006). It is defined as "the use of purposive inflows and outflows of knowledge to accelerate internal innovation, and to expand the markets for external use of innovation, respectively" (Dahlander \& Gann, 2010). It thus comprises both outside-in and inside-out movements of technologies and ideas, also referred to as "technology acquisition" and "technology exploitation" (Von Hippel, 2005).

Traditionally, large firms used to rely on internal R\&D to create new products. In many industries, large internal $\mathrm{R} \& \mathrm{D}$ labs were strategic assets and represented a considerable entry barrier for potential rivals. As a result, large firms with extended R\&D capabilities and complementary assets could outperform smaller rivals (Teece, 1986). This process in which large firms discover, develop and commercialize technologies internally has been recognized as the closed innovation model ( Chesbrough, 2003). Because of labor mobility, abundant venture capital and widely dispersed knowledge across multiple public and private organizations, enterprises cannot afford to have innovative ideas on their own, but rather require engaging in alternative innovation practices. As a result, a growing number of firms have moved to an open innovation model to employ both internal and external pathways to exploit technologies and, concurrently, to acquire knowledge from external sources (Chesbrough, 2003).

Open innovation is a relatively new and rich concept and Dahlander and Gann (2010) concluded, after reviewing 150 open innovation papers, that researchers tend to apply different definitions and focus their research on different aspects which makes it hard to build a coherent body of knowledge (di Benedetto, 2010). According to Gassmann (2006) the context of open innovation could be characterized by both the internal and external environment.

Internal context characteristics include company characteristics associated with demographics and strategies. Number of employees, sales, profits, age, location, market share, and ownership type are included in demographics. Strategy characteristics include strategic orientation, aspects or primary objectives of the innovation strategy, incumbents versus new entrants, organizational culture, as well as other purposeful acts that could be associated with open innovation performance (Huizingh, 2011). Even employee characteristics may matter, as Harison and Koski (2010) found that the adoption of open source software supply strategies among software companies was associated with having highly educated employees. 
Poot el al. (2009) observed a trend towards open innovation across industries, but found that this trend was not continuous but composed of shocks, and that the timing between the shocks differs among various industries. Applying open innovation appears to be more a matter of business strategy than a matter of industry trends (Keupp \& Gassmann, 2009), suggesting that for explaining open innovation adoption the internal environment in firms is more important than the external environment.

Gassmann and Enkel (2004) identified three core open innovation processes. In outside-in process, firms strengthen their own knowledge base through the integration of suppliers, customers and external knowledge sourcing increases innovativeness. Deciding on the outside-in process as a firm's core open innovation approach means that the business unit intends to invest in cooperation with suppliers and customers and to integrate the external knowledge gained. Customer and supplier integration, listening posts at innovation clusters, applying innovation across industries, buying IP and investing in knowledge creation are some activities that companies do in outside-in approach.

As inside-out process, firms earn profits by bringing ideas to market, selling IP and multiplying technology by transferring ideas to the outside boundaries of firms. Companies that choose the insideout process as a main process focus on the externalizing of the company's knowledge and innovation in order to bring ideas to market faster than they can through internal development. Many firms do inside-out process by creating profits by licensing IP and/or multiplying technology by transferring ideas to other companies (commercialization and outsourcing).

Concerning coupled process, many firms couple the outside-in and inside-out processes by working in alliances with complementary partners. Many business units that decide on the coupled process as a key process combine the outside-in process with the inside-out process to bring ideas to market. In order to do both, these companies co-operate with other companies in strategic networks.

Many firms choose the same core open innovation process, or select integrated all three processes to the same degree. Each company not only chooses one primary process, but also integrates some elements of the others (Gassmann \& Enkel, 2004). Chesbrough et al. (2006) defined Open Innovation as "the use of purposive inflows and outflows of knowledge to accelerate internal innovation, and to expand the markets for external use of innovation, respectively". Therefore, it comprises both outside-in and inside-out movements of technologies and ideas and they are also referred to as "technology acquisition" and "technology exploitation" (Lichtenthaler, 2008). In a fully open setting, firms combine both technology exploitation and technology exploration in order to create maximum value from their technological capabilities or other competencies ( Chesbrough \& Crowther, 2006; Lichtenthaler, 2008; Van de Vrande et al., 2009).

Van de Vrande et al., (2009) counted three activities associated with technology exploitation: venturing, outward licensing of intellectual property (IP), and the involvement of non-R\&D workers in innovation initiatives. Venturing is defined as starting up new organizations based on internal knowledge. IP also plays an important role in open innovation as a result of the in- and outflows of knowledge (Arora et al., 2001; Chesbrough, 2006; Chesbrough, 2003; Lichtenthaler, 2007). A third method to use internal knowledge is to capitalize on the initiatives and knowledge of current employees, including those who are not employed at the internal R\&D department.

In addition, Van de Vrande et al. (2009) considered five practices associated with technology exploration including customer involvement, external networking, external participation, outsourcing R\&D and inward licensing of IP. Drawing on the work of Von Hippel (2005) users are increasingly regarded not as just passive adopters of innovations, but they may rather develop their own innovations, which producers can imitate. External networking is another important dimension, which is consistently associated with open innovation (Chesbrough et al., 2006). It includes all activities to acquire and keep connections with external sources of social capital, including individuals and 
organizations. It also comprises both formal collaborative projects and more general and informal networking activities. External participations enable the recovery of innovations initially abandoned or the ones, which do not seem to be promising. Enterprises may invest in start-ups and other businesses to find potential opportunities (Chesbrough, 2006; Maula et al., 2006). Such equity investments provide opportunities to further increase external collaboration in case their technologies prove to be valuable (Van De Vrande et al., 2006). Enterprises may also outsource R\&D activities to acquire external knowledge. Technical service providers such as engineering firms and high-tech institutions have also become more essential in the innovation process. Finally, enterprises can externally acquire intellectual property, including the licensing of patents, copyrights or trademarks (Chesbrough, 2006). Dahlander and Gann, (2010) applied the dimensions of inbound versus outbound open innovation and pecuniary versus non-pecuniary interactions. The four cells in the matrix are labeled as acquiring, sourcing, selling, and revealing. Inbound open innovation refers to internal use of external knowledge, while outbound open innovation is associated with external exploitation of internal knowledge, which is also related to the three knowledge processes of knowledge exploration, retention, and exploitation performed either inside or outside a firm's boundaries (Lichtenthaler \& Lichtenthaler, 2009). Bianchi et al. (2011) recognized three inbound and outbound activities, namely licensing agreements (in and out), non-equity alliances, and technical and scientific services (purchase and supply). Widespread modes for Inbound Open Innovation include in-licensing, minority equity investments, acquisitions, joint ventures, R\&D contracts and research funding, purchase of technical and scientific services and non-equity alliances. Typical modes for Outbound Open Innovation are instead include licensing out, spinning out of new ventures, sale of innovation projects, joint venture for technology commercialization, supply of technical and scientific services, corporate venturing investments and non- equity alliances.

On the other hand Herzog (2011) divided open innovation in two aspect namely; Technology sourcing and Technology commercialization. In technology sourcing, firms can use Internal R\&D, non-equity alliances, equity alliances and acquisitions. In technology commercialization firms also use External technology exploitation capability, strategic alliances and divestment of firm units.

Concerning collaboration and value network, Lee et al. (2010) defined three modes for open innovation namely including customer-provider, Strategic alliance, and Inter-firm alliance. In Exploration (R\&D), in customer-provider mode, companies implement funding, licensing, outsourcing, strategic alliance uses R\&D partnership, joint-venture, and inter-firm alliance use network. On the other hand, however, in Exploitation Customer-provider, Strategic alliance, and Inter-firm alliance use outsourcing, partnership, and network respectively. Lee et al. (2010) listed eight kinds of innovation activities including training for innovation, marketing for innovation, introduction of external knowledge, external R\&D for innovation, organizational innovation, supports of product/process innovation, internal R\&D for innovation, introduction of capital goods (facilities, machines, tools).

\section{Research Methodology}

After reviewing the literature on open innovation, a list of practices which were used by companies was(Teece, 1986) created. Seven experts and managers in power industry were interviewed. They finally chose 16 practices that are more common in Iran especially in power industry. Table 1 illustrates these practices and researcher who proposed them. The data of this research is gathered from firms, which concentrate their activities in Power industry in Iran. After gathering of various practices used for open innovation mentioned in literature of open innovation, we interviewed with 15 managers and experts of innovation and categorized these practices in 16 practices. Some of these methods have been eliminated because they are not very prevalent in this industry. 264 electronic questionnaires were distributed. 127 questionnaires were received by authors that showed $48 \%$ rate of return for questionnaires. Because of having missed data, 9 questionnaires were eliminated. 
Table 1

Open Innovation Practices

\begin{tabular}{|c|c|}
\hline Variable (activities) & Researchers \\
\hline Inside-out Venture Capital & $\begin{array}{l}\text { Bianchi et al., 2011; Chesbrough, 2002; Gassmann \& Enkel, 2004; } \\
\text { Lord et al., } 2002\end{array}$ \\
\hline $\begin{array}{l}\text { Acquisition of innovative } \\
\text { projects }\end{array}$ & Bianchi et al., 2011; Chesbrough, 2002; Granstrand, 2004 \\
\hline Acquisition of other firm & $\begin{array}{l}\text { Gassmann \& Enkel, 2004; Harison \& Koski, 2010; Van De Vrande et } \\
\text { al., } 2006\end{array}$ \\
\hline Minority equity & Harison \& Koski, 2010; Van De Vrande et al., 2006 \\
\hline $\begin{array}{l}\text { Purchasing of technical and } \\
\text { scientific services }\end{array}$ & $\begin{array}{l}\text { Granstrand, 2004; Lord et al., 2002; Steensma \& Corley, 2000; Von } \\
\text { Hippel, } 2005\end{array}$ \\
\hline Licensing in & Chiaroni et al., 2010; Granstrand, 2004 \\
\hline $\begin{array}{l}\text { Outsourcing R\&D } \\
\text { contract }\end{array}$ & Chiaroni et al., 2010; Granstrand, 2004; Steensma \& Corley, 2000 \\
\hline Technology Scanning & $\begin{array}{l}\text { Chesbrough, 2002; Chiaroni et al., 2010; Keupp \& Gassmann, 2009; } \\
\text { Teece, } 1986\end{array}$ \\
\hline Spin offs and incubators & $\begin{array}{l}\text { BurgeSmani \& Wheelwright, 2004; H. Chesbrough, 2006; } \\
\text { Chesbrough, 2002; Gassmann \& Enkel, } 2004\end{array}$ \\
\hline Divestment(123) & $\begin{array}{l}\text { Christensen \& Overdorf, 2000; Gassmann \& Enkel, 2004; } \\
\text { Granstrand, 2004; Lee et al., 2010; Lichtenthaler, 2008; Von Hippel, } \\
2005\end{array}$ \\
\hline $\begin{array}{l}\text { Creation and selling of } \\
\text { innovative } \\
\text { Projects }(123)\end{array}$ & $\begin{array}{l}\text { Granstrand, 2004; Lichtenthaler, 2008; Lichtenthaler \& } \\
\text { Lichtenthaler, } 2009\end{array}$ \\
\hline Outside-in Venture Capital & Bianchi et al., 2011; Granstrand, 2004; Huizingh, 2011 \\
\hline Licensing out (123) & $\begin{array}{l}\text { Arora et al., 2001; Chiaroni et al., 2010; Gassmann, 2006; Gassmann } \\
\& \text { Enkel, 2004; Granstrand, } 2004\end{array}$ \\
\hline $\begin{array}{l}\text { Supply technical and } \\
\text { scientific services }\end{array}$ & $\begin{array}{l}\text { Chiaroni et al., 2010; Gassmann, 2006; Granstrand, 2004; Herzog, } \\
\text { 2011; Runge, } 2006\end{array}$ \\
\hline Performing contract $R \& D$ & $\begin{array}{l}\text { Gassmann \& Enkel, 2004; Granstrand, 2004; Herzog, 2011; } \\
\text { Lichtenthaler \& Ernst, 2009 }\end{array}$ \\
\hline Leakage of technology & $\begin{array}{l}\text { Bianchi et al., 2011; Chesbrough, 2003; Granstrand, 2004; Herzog, } \\
\text { 2011; Von Hippel, } 2005\end{array}$ \\
\hline
\end{tabular}

Fig. 1 shows the characteristics of the sample.

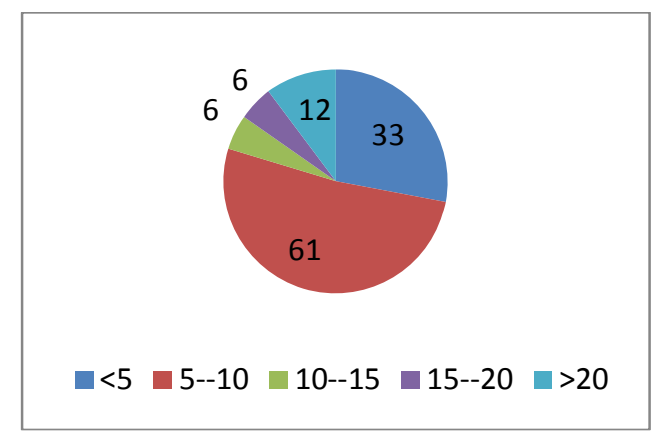

Professional experiences

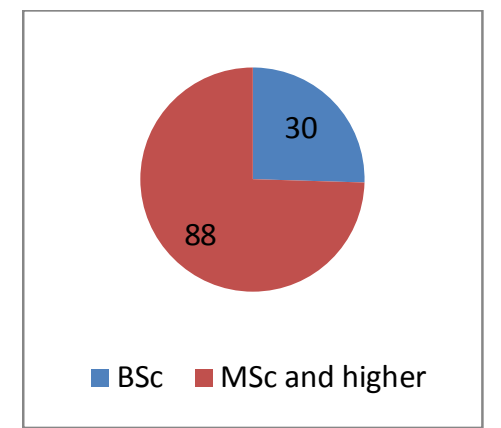

Educational background

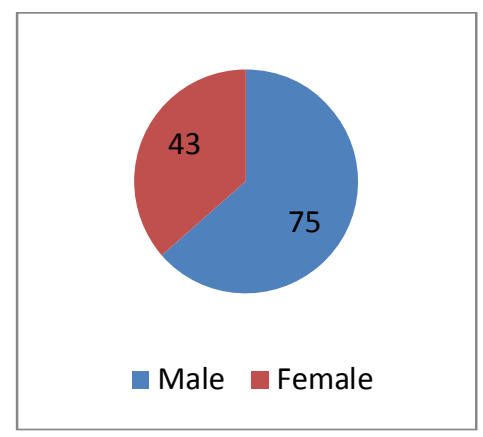

Gender

Fig. 1. The frequencies of personal characteristics of participants

The questionnaire had 16 questions. Items of constructs are assessed with a 5-Likert scale ranging from 1 to 5 with the following equivalences, "1: very low"; " 2 : low"; " 3 : neutral"; " 4 : high"; " 5 : 
very high'. In order to assess the reliability, the internal consistency of each domain was calculated using Cronbach's $\alpha$. Instruments with Cronbach's $\alpha$ value of 0.70 or greater are considered to have satisfactory internal consistency. Cronbach's $\alpha$ value for the total score was 0.89 .

\section{Analysis of research results}

Research method is used for this article is descriptive-correlation. To categorize these practices Exploratory Factor Analysis was used. SPSS 21 was used to perform this statistical method. Factor analysis is a statistical tool used to reduce a large amount of data to a small number of factors (in this case key open innovation approach), to detect the presence of meaningful patterns among the original variables, and to extract the main service factors representing relationships among sets of many interrelated variables. First the Kaiser-Mayer-Olkin (KMO) test and Bartlett's test of sphericity were performed. The KMO test measures the adequacy of a sample in terms of the distribution of values, for the execution of factor analysis. An acceptable value for the KMO test is greater than 0.5. Bartlett's test of Sphericity determines whether the correlation matrix is an identity matrix. If an identity matrix exists, then, factor analysis will be meaningless. Coefficients used to interpret common factors are in bold. Extraction method: principal component analysis. Rotation method: varimax with Kaiser normalization. According to the result of the KMO measurement value of a sampling adequacy of 0.773 , the data were deemed to be appropriate for the analysis. Bartlett's test of sphericity was high at 0.00027 which shows a probability value lowers than 0.001 . This result indicated that correlations do exist among some of the response categories. Both the Bartlett's test of sphericity and the Kaiser-Meyer-Olkin measure of sampling adequacy verified the use of factor analysis for this research.

Table 2

KMO and Bartlett's Test

Kaiser-Meyer-Olkin Measure of Sampling Adequacy.

0.773 Approx. Chi-Square

1379

Bartlett's Test of Sphericity

df 120

Sig.

Table 3

Total variance explained

\begin{tabular}{ccccccc}
\hline \multirow{2}{*}{ Component } & \multicolumn{3}{c}{ Initial Eigenvalues } & \multicolumn{3}{c}{ Rotation Sums of Squared Loadings } \\
\cline { 2 - 6 } & Total & \% of Variance & Cumulative \% & Total & \% of Variance & Cumulative \% \\
\hline 1 & 6.303 & 39.392 & 39.392 & 3.417 & 21.357 & 21.357 \\
2 & 2.317 & 14.484 & 53.876 & 3.132 & 19.575 & 40.932 \\
3 & 1.517 & 9.482 & 63.358 & 3.111 & 19.445 & 60.377 \\
4 & 1.304 & 8.15 & 71.508 & 1.781 & 11.131 & 71.508 \\
5 & 0.858 & 6.613 & 78.121 & & & \\
6 & 0.694 & 4.339 & 82.46 & & & \\
7 & 0.599 & 3.741 & 86.201 & & & \\
8 & 0.528 & 3.299 & 89.5 & & & \\
9 & 0.425 & 2.653 & 92.153 & & & \\
10 & 0.325 & 2.033 & 94.186 & & & \\
11 & 0.295 & 1.841 & 96.028 & & & \\
12 & 0.24 & 1.5 & 97.528 & & & \\
13 & 0.152 & 0.947 & 98.475 & & & \\
14 & 0.122 & 0.764 & 99.239 & & & \\
15 & 0.089 & 0.559 & 99.798 & & & \\
16 & 0.032 & 0.202 & 100 & & & \\
\hline
\end{tabular}


After running Principal Component Analysis, as it is shown Table 3 (after varimax rotation) there are just four factors with Eigenvalue more than 1. According to rotation sum of squared loading, these four factors totally explain 71.5 percent of variances.

Factor loadings are the correlations of the variables with a factor. The realistic meaning of a factor can be synthesized by combining those variables that have a relatively high factor loading after performing a principal component factor analysis with varimax rotation. Variables are loaded maximally to only one factor and minimally to the remaining factors. This analysis provides a clearer picture of what these factors represent. The resulting key safety factor dimensions are identified in Table 4.

Factor 1, which we refer it as Acquisition of Firms and Projects includes: Inside- out Venture Capital, Acquisition of innovative projects, Acquisition of other firm, and Minority equity. Four items explained $21.36 \%$ of the rotation variance. All four practices are associated with gain ownership of properties such as projects, part of a firm or whole one.

Factor 2 is the gain-related factor without purchasing any properties. We call it Acquisition of Technology without purchasing, constitutes Purchasing of technical and scientific services, Licensing in, Outsourcing R\&D Contract, and Technology Scanning. These are the ways that companies can obtain outside knowledge and ideas to use the ability of other companies and organization to innovate without purchasing any properties.

Factor 3 refers to the practices that companies use for making over some part of their projects or companies to earn revenues. It is called Spin offs and Divestment including Spin offs and incubators, Divestment, Creation and selling of innovative Projects, and Outside-in Venture Capital. By doing these practices companies follow the approach of making themself smaller and more diversified.

Factor 4 also covers four items: Licensing out, Supply technical and scientific services, Performing contract R\&D, and Leakage of technology. We called this factor Selling out and Leakage of technology.

Table 4

Rotated Component Matrix

\begin{tabular}{lcccc}
\multicolumn{1}{c}{ Items (Practices) } & \multicolumn{4}{c}{ Component } \\
\hline Inside- out Venture Capital & 1 & 2 & 3 & 4 \\
Acquisition of innovative projects & 0.585 & 0.316 & 0.531 & 0.057 \\
Acquisition of other firm & 0.825 & 0.267 & 0.089 & 0.053 \\
Minority equity & 0.814 & 0.344 & -0.004 & 0.184 \\
Purchasing of technical and scientific services & 0.839 & 0.333 & 0.029 & 0.051 \\
licensing in & 0.334 & 0.758 & 0.08 & -0.003 \\
Outsourcing R\&D Contract & -0.092 & 0.748 & 0.208 & 0.318 \\
Technology Scanning & 0.261 & 0.78 & 0.01 & 0.146 \\
spin offs and incubators & 0.238 & 0.83 & 0.179 & 0.157 \\
Divestment & 0.214 & 0.186 & 0.719 & 0.089 \\
Creation and selling of innovative Projects & 0.276 & 0.17 & 0.793 & -0.023 \\
Outside-in Venture Capital & -0.024 & 0.16 & 0.699 & 0.184 \\
Licensing out & -0.074 & 0.003 & 0.841 & 0.052 \\
Supply technical and scientific services & 0.127 & -0.174 & 0.371 & 0.755 \\
performing contract R\&D & -0.014 & 0.117 & 0.346 & 0.656 \\
Leakage of technology & 0.222 & 0.262 & 0.328 & 0.713 \\
\hline Exily & 0.199 & 0.495 & -0.18 & 0.665 \\
\hline
\end{tabular}

Extraction Method: Principal Component Analysis.

Rotation Method: Varimax with Kaiser Normalization.

To rank these factors, which will be called Open Innovation Approaches from now, Friedman test has been run. Table 5 shows the results of this test. It could be observed that Selling out and Leakage of technology by having the highest mean is the first approach and Spin offs and Divestment is the last one. 


\section{Table 5}

Results of Friedman test for ranking approaches

\begin{tabular}{lcccc}
\hline \multicolumn{1}{c}{ Approaches } & Mean Rank & Rank & Chi-Square & Significance Level \\
\hline Acquisition of Firms and Projects & 2.69 & 3 & & \\
Acquisition of Technology & 3.66 & 2 & \multirow{2}{*}{123.74} & 0.001 \\
Spin offs and Divestment & 1.78 & 4 & & \\
Selling out and Leakage of technology & 3.95 & 1 & & \\
\hline
\end{tabular}

\section{Conclusion}

Most of the researches about open innovation, have been conducted in developed countries. Therefore, study on practices used by developing countries is crucial to help their companies understand open innovation and its practices. Moreover, categorizing these practices to understand approaches among bunch of open innovation practices will be great helpful tool for managers.

In this article, we have gathered the practices using by companies to do open innovation. After that, we have tested these practices in Power Industry in Iran and categorized them into four approaches by using exploratory factor analysis. These four approaches explain 71.5 percent of shared variance. Further, all individual items were best correlated with their conceptual original factors. To rank these approaches and to recognize which approach is used more than other by these companies Friedman Test were used. The results of this test showed that companies which are in Power industry use Selling out and Leakage of technology, Acquisition of Technology, Acquisition of Firms and Projects, and Spin offs and Divestment, respectively.

To the best of our knowledge, there are only a few studies about science and technology parks and incubators in Iran. On the other hand, in Power industry, in the lack of enough experts and R\&D centers, companies prefer transferring technology or getting help from others to creating it, therefore, Selling out and Leakage of technology and Acquisition of Technology are more prevalence.

\section{Acknowledgment}

The authors would like to thank the anonymous referees for constructive comments on earlier version of this paper.

\section{References}

Arora, A., Fosfuri, A., \& Gambardella, A. (2001). Markets for technology and their implications for corporate strategy. Industrial and corporate change, 10(2), 419-451 .

Bianchi, M., Cavaliere, A., Chiaroni, D., Frattini, F., \& Chiesa, V. (2011). Organisational modes for Open Innovation in the bio-pharmaceutical industry: An exploratory analysis. Technovation, 31(1), 22-33.

BurgeSmani, R. A., \& Wheelwright, S. C. (2004). Strategic management of technology and innovation. READING, 1,1 .

Chesbrough, H. (2006) Open business models: Harvard Business Press.

Chesbrough, H., \& Crowther, A. K. (2006). Beyond high tech: early adopters of open innovation in other industries. $R \& d$ Management, 36(3), 229-236.

Chesbrough, H., Vanhaverbeke, W., \& West, J. (2006). Open innovation: a new paradigm for understanding industrial innovation. Open innovation: researching a new paradigm, 1-12 .

Chesbrough, H. W. (2002). Making sense of corporate venture capital. Harvard Business Review, 80(3), 90-99 .

Chesbrough, H. W. (2003 .(Open innovation: The new imperative for creating and profiting from technology: Harvard Business Press. 
Chesbrough, H. W. (2006). The era of open innovation. Managing innovation and change, 127(3), 34-41.

Chiaroni, D., Chiesa, V., \& Frattini, F. (2010 .(Unravelling the process from Closed to Open Innovation: evidence from mature, asset-intensive industries. R\&d Management, 40(3), 222-245 .

Christensen, C. M., \& Overdorf, M. (2000). Meeting the challenge of disruptive change. Harvard Business Review, 7 .77-66,(2)8

Dahlander, L., \& Gann, D. M. (2010). How open is innovation? Research Policy, 39(6), 699-709 .

di Benedetto, A. (2010). Comment on 'Is open innovation a field of study or a communication barrier to theory development?'. Technovation, $30(11.557,($

Gassmann, O. (2006). Opening up the innovation process: towards an agenda. R\&d Management, $36(3), 223-228$.

Gassmann, O., \& Enkel, E. (2004). Towards a theory of open innovation: three core process archetypes. Paper presented at the R\&D management conference.

Granstrand, O. (2004). The economics and management of technology trade: towards a pro-licensing era? International Journal of Technology Management, 27(2), 209-240 .

Harison, E., \& Koski, H. (2010). Applying open innovation in business strategies: Evidence from Finnish software firms. Research Policy, 39(3), 351-359 .

Herzog, P. (2011). Open and closed innovation: Springer.

Huizingh, E. K. (2011). Open innovation: State of the art and future perspectives. Technovation, $31(1), 2-9$.

Keupp, M .M., \& Gassmann, O. (2009). Determinants and archetype users of open innovation. $R \& d$ Management, 39(4), 331-341.

Lee, S., Park, G., Yoon, B., \& Park, J. (2010). Open innovation in SMEs-An intermediated network model. Research Policy, 39(2), 290-300 .

Lichtenthaler, U. (2007). Hierarchical strategies and strategic fit in the keep-or-sell decision. Management Decision, 45(3), 340-359.

Lichtenthaler, U. (2008). Open innovation in practice: an analysis of strategic approaches to technology transactions. Engineering Management, IEEE Transactions on, 55(1), 148-157 .

Lichtenthaler, U., \& Ernst, H. (2009). Opening up the innovation process: the role of technology aggressiveness. $R \& d$ Management, 39(1), 38-54 .

Lichtenthaler, U., \& Lichtenthaler, E. (2009). A Capability-Based Framework for Open Innovation: Complementing Absorptive Capacity. Journal of Management Studies, 46(8), 1315-1338 .

Lord, M. D., Mandel, S. W., \& Wager, J. D. (2002). Spinning out a star. Harvard Business Review, 80(6), 115

Maula, M. V., Keil, T., \& Salmenkaita, J.-P. (2006). Open innovation in systemic innovation contexts. Open innovation: researching a new paradigm, 241-257 .

Poot, T., Faems, D., \& Vanhaverbeke, W. (2009). Toward a dynamic perspective on open innovation: A longitudinal assessment of the adoption of internal and external innovation strategies in the Netherlands. International Journal of Innovation Management, 13(02), 177-200 .

Runge, W. (2006). Innovation, research and technology intelligence in the chemical industry: integrated business, technical and systems approaches: Fraunhofer-IRB-Verlag.

Steensma, H. K., \& Corley, K. G. (2000). On the performance of technology-sourcing partnerships: the interaction between partner interdependence and technology attributes. Academy of Management Journal, 43(6), 1045-1067 .

Teece, D. J. (1986). Profiting from technological innovation: Implications for integration, collaboration, licensing and public policy. Research Policy, 15(6), 285-305 .

Van de Vrande, V., De Jong, J. P., Vanhaverbeke, W., \& De Rochemont, M. (2009). Open innovation in SMEs: Trends, motives and management challenges. Technovation, 29(6), 423-437 .

Van De Vrande, V., Lemmens, C., \& Vanhaverbeke, W. (2006). Choosing governance modes for external technology sourcing .R\&d Management, 36(3), 347-363 . 
2814

Von Hippel, E. (2005). Democratizing innovation: The evolving phenomenon of user innovation. Journal für Betriebswirtschaft, 55(1), 63-78 . 